\title{
AN ANALYSIS ON HOW HOAX NEWS SPREAD THROUGH SOCIAL MEDIA
}

\author{
A. Musdalifah Arif \& Andi Miswar \\ ${ }^{1}$ Universitas UIN Alauddin Makassar \\ Correspondence email: amusdalifaharif.ifatari@gmail.com
}

\begin{abstract}
This article discusses the dissemination of hoax information via social media. The purpose of this study was to determine the flow of hoax information dissemination through social media and to determine the impact of hoax information dissemination in the community. This qualitative research used online media and literature review as its resources of the data. The results of this study provide an understanding of the flow of hoax information dissemination, starting with making information that is adopted from public opinion and then developed into articles, spiced with lies, spread through social media using anonymized accounts, so that people who read it redistribute other communities and so on. While the impact, results in social interaction of the community, initially their relationship was fine as family, neighbors or friends. But because they often consume hoaxes, the the problems occurred among them.
\end{abstract}

Keywords: Hoax Information, Social Media,

\begin{abstract}
Abstrak
Artikel ini membahas bagaimana penyebaran informasi hoax melalui media sosial dan apa dampak penyebaran informasi hoax tersebut pada masyarakat. Sumber data dari jenis penelitian deskriptif kualitatif ini diperoleh dari beberapa literatur dan media online yang melaporkan beberapa informasi hoax di akhir-akhir ini sering terjadi. Sementara untuk mengetahui dampaknya, beberapa individu yang punya pengalaman menerima berita hoax menjadi informan penelitian ini. Hasil penelitian menunjukkan bahwa penyebaran informasi hoax, dimulai dengan pembuatan informasi yang diadopsi dari opini masyarakat kemudian dikembangkan menjadi artikel, dibumbui kalimat bohong, disebarkan melalui media sosial menggunakan akun anonim, sehingga masyarakat yang membacanya menyebarkan kembali ke masyarakat lain dan seperti itu seterusnya. Sedangkan dampaknya, berakibat pada interaksi sosial masyarakat, mulanya hubungan mereka baik-baik saja sebagai keluarga, tetangga maupun sahabat. Tetapi karena mereka kerap kali mengkonsumsi hoax, maka perdebatan hingga perseteruan terjadi diantara mereka.
\end{abstract}

Kata Kunci: Informasi Hoax, Media Sosial, 


\section{Pendahuluan}

Informasi bukan lagi sesuatu yang sulit untuk didapatkan oleh masyarakat, bahkan tanpa dicari sekalipun informasi akan datang dengan sendirinya, seperti halnya ketika membuka facebook dengan niat ingin mengirim pesan kepada teman atau sanak keluarga dan seketika melihat beranda dan tiba-tiba ada artikel yang lewat dan dibagikan oleh rekan facebook mengenai gempa yang terjadi di palu atau banjir yang terjadi di Jakarta, secara tidak sengaja informasi ini di dapatkan walau tanpa dicari. Contoh lain misalnya, ketika sedang membuka story teman di whatsapp dan secara tidak sengaja ada info mengenai seminar nasional ataupun seminar internasional yang kebetulan free atau gratis dan tersedia pula fasilitas seperti buku dan sertifikat, otomatis niat untuk mengikuti seminar pasti ada. Kedua contoh tersebut merupakan contoh kasus bahwasanya saat ini informasi akan datang dengan sendirinya tanpa dicari.

Informasi begitu penting bagi siapa saja. Baik itu informasi lokal maupun informasi mancanegara telah menjadi kebutuhan yang mesti diketahui dan didapatkan oleh setiap individu. Beragam alasan tiap individu dalam mengakses informasi tersebut, dari yang sekedar ingin tahu perkembangan terbaru suatu objek hingga untuk mendalami suatu informasi. Kelembagaan informasi tidak dibatasi oleh batas-batas ruang geografis secara tegas, siapa pun dan dari mana pun orang tersebut berasal, dianggap mempunyai hak untuk mendapatkan informasi yang dibutuhkannya (Yusup, 2009: 323). Mengetahui kebutuhan masyarakat akan informasi yang sangat tinggi maka banyak penyedia informasi membuat media atau sarana pencarian dan penemuan informasi yang bebas akses. Sehingga informasi yang tersebar hingga saat ini jumlahnya makin hari makin bertambah apalagi dengan semakin mudahnya teknologi informasi komunikasi dalam memproduksi dan menyebarkan informasi. Tidak heran jika masa kini disebut masa keterbukaan akses informasi, karena orang-orang saat ini, siapapun, kapanpun dan dimanapun mereka dapat secara bebas mengakses informasi selama memiliki alat teknologi seperti gadget, laptop, komputer, dan terhubung ke jaringan internet, semua informasi bisa didapatkan dengan bantuan teknologi dan jaringan.

Manusia mau tidak mau harus menghadapi ledakan informasi yang terjadi saat ini. Ledakan informasi membawa pengaruh baik dan pengaruh buruk bagi masyarakat pembaca. Pengaruh baik yang dimaksud adalah masyarakat pembaca dapat dengan mudah mencari, menemukan dan mengakses informasi secara bebas sehingga informasi yang mereka peroleh dapat berubah menjadi sebuah pengetahuan. Sedangkan pengaruh buruk dari ledakan informasi bagi masyarakat pembaca yakni banyaknya kehadiran informasi tidak benar atau informasi bohong, fitnah atau hoax yang ikut meledak dengan memanfaatkan internet dan media sosial. Ledakan informasi sangat terhubung dengan pesatnya teknologi yang tidak hanya menghadirkan dampak positif di lingkungan masyarakat tapi juga menghadirkan dampak negatif dari teknologi, penyalahgunaan teknologi oleh masyarakat semakin hari semakin merajalela. Salah satu contoh dari penyalahgunaan teknologi di bidang informasi adalah pembuatan dan penyebaran informasi hoax di media sosial. 
Dengan maraknya informasi hoax atau informasi yang tidak berkualitas beredar di dunia maya membuat alur informasi berjalan tidak beraturan, tidak sedikit dari masyarakat yang percaya akan isi yang tersirat dalam artikel-artikel hoax yang beredar di media sosial. Parahnya para pengguna media sosial terbiasa membaca hingga menyebarkan berita hoax tanpa meneliti dan mencari keabsahan sebuah informasi terlebih dahulu.

Pembuatan dan penyebaran informasi hoax di lingkungan masyarakat terjadi dikarenakan adanya penyalahgunaan alat teknologi dan media sosial. Masyarakat masa kini banyak yang menerima berita lewat media sosial karena di zaman modern ini banyak masyarakat yang mulai menggunakan media sosial untuk berkomunikasi dan menerima informasi atau berita-berita yang mulai menyebar (Syaifullah, 2018: 3). Banyaknya berita atau informasi yang beredar di media sosial membuat hoax susah di kenali, sehingga masyarakat atau para pengguna media sosial terbiasa mengkonsumsi hoax. Para pengguna media sosial juga kadang kala berperilaku acuh tak acuh dalam menerima dan membagikan sebuah informasi, banyak dari mereka hanya asal membaca dan membagikan informasi tanpa tau kebenaran yang sebenarnya. informasi hoax yang hari demi hari kian meningkat, membawa akibat buruk terhadap interaksi masyarakat, baik itu interaksi di dunia maya maupun interaksi di dunia nyata. Tidak sedikit masyarakat pengguna media sosial yang bersiteru hingga melontarkan kalimat-kalimat kasar, kalimat melecehkan, penistaan, dan kalimat mengancam.

Untuk menanggulangi kerusuhan yang terjadi di tengah-tengah masyarakat akibat dari pembuatan dan penyebaran informasi hoax di media sosial maka pemerintah mengeluarkan aturan hukum, yakni Undang-Undang No.11 tahun 2008 dengan dikeluarkannya Undang-Undang ini penyebar berita hoax dapat dijerat dengan masa hukuman selama 7 tahun sesuai dengan pasal 28 ayat 1 dan dalam pasal 45 Menyebutkan bahwa setiap orang yang dengan sengaja dan atau tanpa hak menyebarkan berita bohong dan menyesatkan, ancamannya bisa terkena pidana maksimal enam tahun dan denda maksimal Rp 1 miliar (Darwin, 2018: 3). UndangUndang yang telah diberlakukan ini, hakekatnya masih saja disepelekan oleh sebagian masyarakat pengguna media sosial tapi tak sedikit pula yang telah menyadari akan konsekuensi dari membuat dan menyebarkan informasi bohong/hoax.

\section{Metodologi}

Penelitian ini bersifat deskriptif kualitatif, deskripsi kualitatif adalah suatu penelitian kontekstual yang menjadikan manusia sebagai informan dan disesuaikan dengan situasi yang wajar dalam kaitannya dengan pengumpulan data yang pada umumnya bersifat kualitatif (Lexy.J, 2001: 34). Kualitatif bertujuan untuk menjelaskan dan mendeskripsikan sebuah fenomena melalui pengumpulan data. Fenomenologi pada dasarnya berpandangan bahwa apa yang nampak di permukaan baru bisa dipahami atau dijelaskan manakala bisa mengungkap atau membongkar apa yang tersembunyi dalam dunia kesadaran atau dunia pengetahuan si manusia pelaku, realitas itu sesungguhnya bersifat subyektif dan maknawi yang bergantung pada persepsi, pemahaman, pengertian dan anggapan-anggapan seseorang (Faisal, 2015: 
3). Penelitian ini dilakukan dengan memantau penyebaran informasi hoax di media sosial. Peneliti mendapatkan data melalui dua sumber yakni sumber data primer dan data sekunder. Metode pengumpulan data yang dilakukan dalam penelitian ini juga ada dua yakni library research dan field research, library research disini peneliti mendapatkan data dari literatur-literatur yang disediakan oleh perpustakaan dan field research disini peneliti mendapatkan data dari hasil observasi partisipatif, wawancara tidak terstruktur dan dokumentasi, dokumentasi yang di maksud adalah peneliti melakukan screen capture terhadap beberapa informasi hoax yang menyebar di media sosial. Teknik yang dilakukan peneliti dalam menganalisis data ada tiga yakni reduksi data, penyajian data dan verifikasi.

\section{Hasil Penelitian}

Alur penyebaran informasi ini dimulai dengan pembuatan informasi yang diadobsi dari opini masyarakat yang kemudian dikembangkan menjadi artikel, dibumbui kalimat-kalimat bohong, kemudian disebarkan melalui group yang disebarkan oleh oknum-oknum yang tidak bertanggung jawab menggunakan akun anonym ataupun akun bajakan, sehingga masyarakat yang tanpa sengaja melihatnya dan membacanya tersentuh hingga menyebarkannya kembali ke masyarakat yang lain dan seperti itu seterusnya, penyebaran informasi hoax ini melalui aplikasi-aplikasi media sosial seperti facebook, whatsapp, instagram, twitter dan youtube. Bisa saja masyarakat maya menyebarkan lewat beranda maupun pesan dan group facebook, story whatsapp, status di Instagram, coretan di twitter dan video video youtube. Proses penyebarannya juga bisa melalui pesan pribadi maupun melalui pesan berantai yang di kirim melalui group dengan salah satu menu di setiap aplikasi media sosial yakni share atau bagikan.

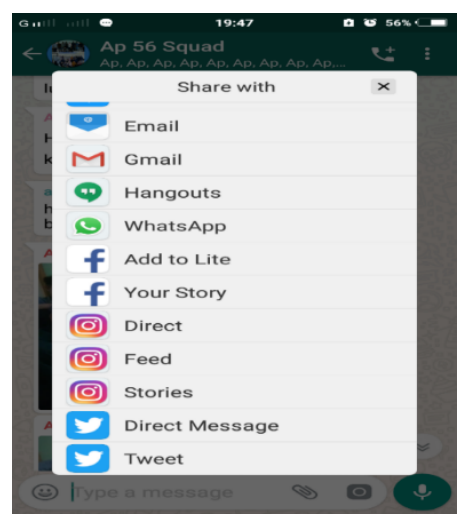

Gambar 1. Hasil Observasi Peneliti

Menu share yang ada di setiap aplikasi media sosial sangat membantu proses penyebaran berita hoax di antara aplikasi. Informasi hoax yang awalnya hanya terdapat di beranda google, yang kemudian dibagikan di beranda fb, story dan pesan, sehingga berita atau artikel tersebut didapati dan dibaca oleh masyarakat maya yang awam pengetahuan mengenai informasi hoax, kemudian mereka 
menganggap berita yang di dapatkan adalah informasi yang benar adanya lalu membagikan unggahan tersebut ke berandanya, beranda teman atau kenalannya, dan membagikan di beranda group yang dia miliki. Informasi tersebut turut dibagikan melalui pesan hingga ke aplikasi media sosial lainnya seperti instagram, whatsapp, twitter dan semacamnya. Sehingga setiap orang yang tidak tau bahwa informasi yang didapatinya adalah informasi hoax juga akan membagikannya seperti yang dilakukan oleh orang pertama dan orang ketiga dan seterusnya berlanjut seperti itu. Prosesnya hanya dengan mengklik satu menu aplikasi yakni kata share atau bagikan maka berita atau informasi tersebut bisa tersebar ke penjuru media sosial, informasi tersebut bisa di bagikan terhadap keluarga, teman, tetangga, kenalan dan bahkan pada orang yang tidak dikenal sekalipun. Melalui media sosial, informasi apa saja baik itu informasi hoax ataupun informasi fakta yang memang betul adanya dapat diketahui oleh setiap orang di indoesia bahkan luar indonesia seperti malaysia, singapura, arab saudi, amerika dan negara lainnya selama memiliki akun aplikasi seperti akun facebook, whatsapp, instagram, e-mail dan semacamnya.

Banyaknya informasi hoax yang beredar di media sosial dapat memberi dampak terhadap interaksi sosial, serta kurangnya kemampuan masyarakat dalam menelaah informasi membuat perpecahan atau ketidaksesuaian pendapat semakin menjadijadi sehingga terjadilah pertikaian antar individu, antar kelompok maupun antar individu dan kelompok.imbulnya konflik di tengah masyarakat dikarenakan berita hoax, sangat berakibat terhadap interaksi sosial masyarakat, yang tadinya mereka adalah teman dekat di dunia nyata, mereka adalah tetangga, dan keluarga tapi karena terjadinya ketidaksesuaian pendapat dikarenakan termakan hoax yang dibacanya maka terjadilah pertikaian diantara mereka hingga nekat memutuskan tali silaturahmi. Yang dulunya ketika bertemu maka mereka akan bertegur sapa, saling mengobrol bahas ini itu, arisan sama-sama, chattingan di media sosial, jalan-jalan bareng dan sebagainya. Selain konflik yang terjadi diantara mereka yang sudah saling kenal seperti, keluarga, teman dekat dan tetangga. Konflik lain akibat informasi hoax juga sering terjadi diantara mereka yang tidak atau belum saling kenal di media sosial. Mereka biasanya berkelahi karena ketidaksesuaian pendapat satu sama lain melalui kolom komentar media sosial, saling mengujarkan kalimat kebencian antara satu sama lain, melontarkan kalimat yang tidak sepantasnya, menyumpahi dan sebagainya.

Contoh dipemilu kemarin, tidak sedikit informasi hoax beredar dengan sengaja di media sosial yang sehingga dapat memengaruhi masyarakat dalam menentukan calon dan memicu adu mulut hingga perkelahian dimasyarakat. Dalam pemilu kemarin Informasi hoax yang banyak beredar adalah infromasi mengenai ke dua kandidat capres dan cawapres yakni probowo sandiaga dan jokowi ma'ruf.

Beberapa gambar informasi hoax yang beredar dimasyarakat mengenai calon presiden no urut 1 dan no urut 2: 


\begin{tabular}{|c|c|c|}
\hline G . 4 LIE : & 15:54 & a $6>72 x$ \\
\hline ald & & Buka Gratis \\
\hline
\end{tabular}

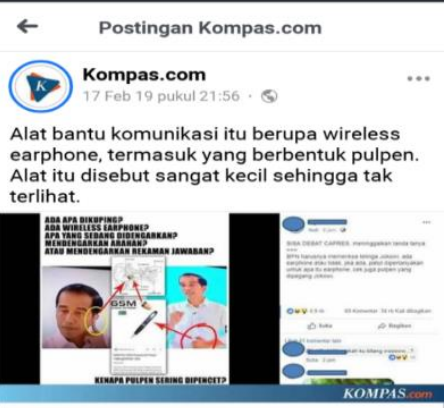

[KLARIFIKASI] Jokowi Pakai Alat Bantu Komunikasi Saat Debat Kedua - Kompas.

Alat bantu komunikasi itu berupa wireless earphone, termasuk yang berbentuk pulp

(C) Tulis komentar.

Gambar 2. Screenshoot Berita Hoax

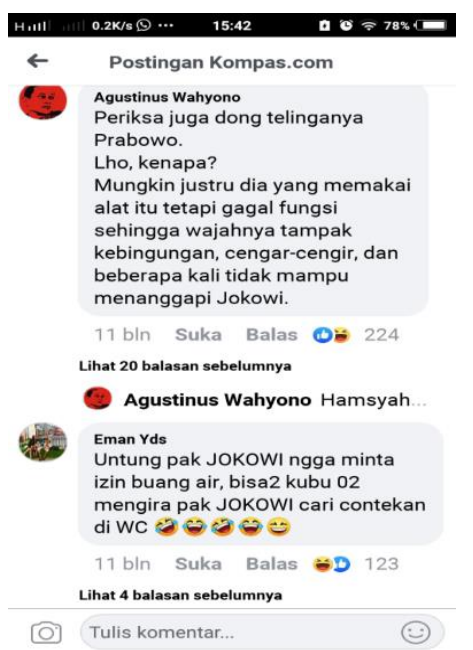

Gambar 3. Screenshoot Berita Hoax 


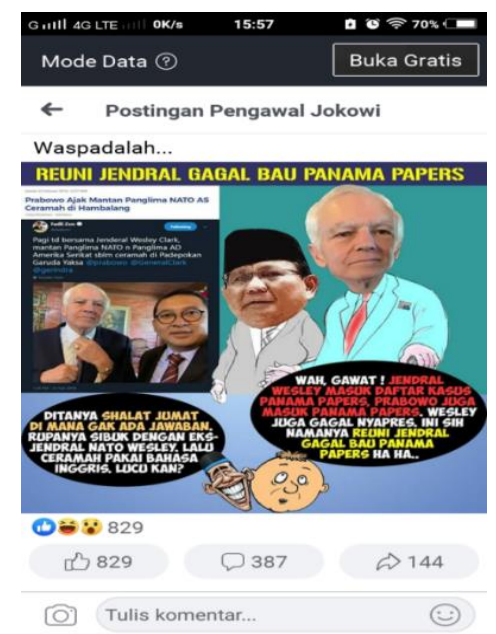

Gambar 4. Screenshoot Berita Hoax

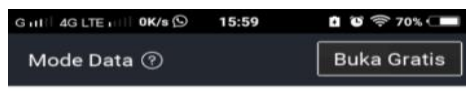

$\leftarrow \quad$ Postingan Pengawal Jokowi

(7) MuNi

orang sebellah otakxa kan sudah stres semua,jadi omonganx dan doaxa dah pada ngelantur.no 1 yes. $11 \mathrm{bln}$ Suka Balas OS 3

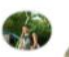

Agung Siswa Adji

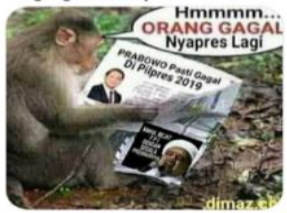

11 bin Suka Balas $4 D D$ Lihat balasan sebelumnya

(1) Nurmals Ehan Anunn Ciews A

(O) Tulis komentar..

Gambar 5. Screenshoot Berita Hoax 


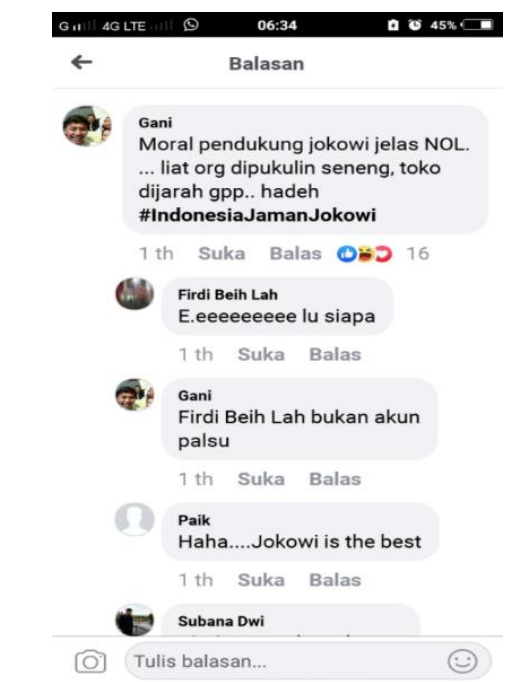

Gambar 6. Screenshoot Berita Hoax

\begin{tabular}{|c|c|}
\hline$\leftarrow$ & Balasan \\
\hline & $\begin{array}{l}\text { Bang Jeff } \\
\text { Ngomong moral..emng moral } \\
\text { lu sendiri Uda bagus Gani.. } \\
\text { sampai Lo hakimi moral } \\
\text { pendukung Jokowi,..otak lu } \\
\text { cetek...sama kaya moral lu yg } \\
\text { suka menuduh...belajar bnyak } \\
\text { Lo dulu ke SD ya....apa itu } \\
\text { Pendidikan Moral..oke Gani }\end{array}$ \\
\hline & 1 th Suka Balas \\
\hline & $\begin{array}{l}\text { Gani } \\
\text { Bang Jeff seburuk } 2 \text { nya w... liat } \\
\text { org dipukulin trs lu bully itu } \\
\text { sedih yah. Aplgi penjarahan } \\
\text { dibenerin. }\end{array}$ \\
\hline & 1 th Suka Balas \\
\hline & $\begin{array}{l}\text { Kianom } \\
\text { Oplas tuh nenek }\end{array}$ \\
\hline & 1 th Suka Balas \\
\hline
\end{tabular}

Gambar 7. Screenshoot Berita Hoax

\section{Diskusi dan Kesimpulan}

Alur penyebaran informasi ini dimulai dengan pembuatan informasi yang diadopsi dari opini masyarakat yang kemudian dikembangkan menjadi artikel, dibumbui kalimat-kalimat bohong, lalu disebarkan melalui group yang disebarkan oleh oknum oknum yang tidak bertanggung jawab menggunakan akun anonym ataupun akun bajakan, sehingga masyarakat yang tanpa sengaja melihatnya dan membacanya tersentuh hingga menyebarkannya kembali kemasyarakat yang lain dan seperti itu seterusnya, penyebaran informasi hoax ini melalui aplikasi-aplikasi media sosial 
seperti facebook, whatsapp, Instagram, twitter dan youtube. Bisa saja masyarakat maya menyebarkan lewat beranda maupun pesan dan group facebook, story whatsapp, status di Instagram, coretan di twitter dan membagikannya dalam bentuk video di youtube. Proses penyebarannya juga bisa melalui pesan pribadi maupun melalui pesan berantai yang di kirim melalui group dengan salah satu menu di setiap aplikasi media sosial yakni share atau bagikan.. Sehingga setiap orang yang tidak tau bahwa informasi tersebut adalah hoax, akan berlomba-lomba membagikannya, baik itu di beranda dan story miliknya maupun milik orang lain. Banyaknya informasi hoax yang tersebar di berbagai aplikasi media sosial seperti facebook, whatsapp, instagram, twitter, dan sebagainya dapat memberikan dampak terhadap interaksi sosial masyarakat, mulai dari perbedaan atau ketidaksesuaian pendapat antara satu sama lain maupun antar kelompok, ras dan agama. Informasi hoax ini dapat menghilangkan toleransi keakraban masyarakat sosial, informasi hoax dapat memecah belah, bisa menimbulkan perang antar keluarga, perang antar saudara bisa juga menimbulkan pelanggaran, pelecehan nama baik, bisa menimbulkan permusuhan, dan lain sebagainya. Serta dampak lainnya yakni masyarakat akan saling memberikan umpatan atau saling mengujarkan kalimat kebencian, menyumpah-nyumpahi, melontarkan kalimat-kalimat yang tidak sopan, saling singgung menyinggung hingga terjadinya pertikaian yang dapat mengakibatkan tali silaturahmi putus, tidak lagi saling sapa menyapa, tidak lagi saling tegur menegur serta tidak lagi menanyakan kabar antara satu sama lain.

Bagi masyarakat maya atau pengguna media sosial, jangan terlalu mudah percaya dengan informasi-informasi yang beredar di media sosial dan sebaiknya, ketika selesai ataupun sebelum membaca sebuah artikel, masyarakat maya seharusnya memeriksa terlebih dahulu ke validan informasi yang telah diterima sebelum mempercayai dan membagikannya kepada orang lain, sehingga informasi hoax tidak tersebar dengan mudahnya dan memengaruhi interaksi sosial. Bagi pemerintah, walaupun undang-undang informasi dan transaksi elektronik telah diberlakukan di indonesia, tapi sayangnya, masih banyak informasi hoax yang berserakan di media sosial. Seharusnya, selain hanya mengeluarkan undang-undang ite, pemerintah juga perlu mengawasi setiap pergerakan informasi di media sosial agar informasi hoax tidak merambat dan membelenggu masyarakat maya. Dan mungkin bagus jika disetiap aplikasi media sosial ada menu keamanan dimana setiap ada informasi yang terdeteksi hoax maka informasi tersebut akan terblokir bersama dengan akun yang membagikannya. Menu seperti ini pasti akan membuat informasi hoax tidak lagi berceceran dimana-mana, tidak ada lagi informasi yang akan membuat kerusuhan ditengah-tengah masyarakat, dan hoax akan terbasmihkan. Bagi mahasiswa, jika dengar kata mahasiswa pasti pikiran masyarakat, mereka adalah orang-orang yang tergolong cerdas, mahasiswa yang katanya sebagai agen pembawa perubahan seharusnya mampu membuat informasi hoax tidak merambat di media sosial, salah satunya turun lansung ke masyarakat melakukan penyuluhan atau melakukan kegiatan literasi agar masyaratakat tidak gampang menelan mentah-mentah informasi yang didapat dan mengajarkan masyarakat bagaimana cara menyaring dan memilah informasi yang ada di media sosial. Bagi masyarakat umum, sebaiknya jangan mudah terprovokasi terhadap 
informasi-informasi pada media apapun, karena itu bisa jadi informasi yang dapat mempengaruhi kepercayaan anda pada seseorang maupun kelompok atau hingga merendahkan pihak lain.

\section{Daftar Pustaka}

Abdul, A. (2015). Menyusun Rancangan Penelitian. Dalam B. Bungin, Analisis Data Penelitian Kualitatif (hal. 41). Jakarta: Rajawali Pers.

Aulia, D. P. (2018). Memerangi Berita Bohong Di Media Sosial: Studi Terhadap Gerakan Masyarakat Anti Fitnah Indonesia. 2018: Fakultas Ilmu Dakwah Dan Komunikasi.

Darwin, I. P. (2018). Peran Kepolisian Dalam Penyidikan Tindak Pidana Penyebaran Berita Bohong (HOAX). Bandar Lampung: Universitas Lampung.

Faisal, S. (2015). Filososfi Dan Akar Tradisi Penelitian Kualitatif. Dalam B. Bungin, Analisis Data Penelitian Kualitatif. Jakarta: Rajawali Pers.

Faizal. (2012). Teknologi Informasi. Makassar: Alauddin Pers.

Febrian, J. (2007). Kamus Komputer Dan Teknologi Informasi . Bi-Obses: Bandung.

Hijeruddin. (2018). Eksistensi Group Facebook Info Kejadian Kota Makassar (INKAM) Sebagai Sumber Informasi Masyarakat Di Kota Makassar. Makassar: Fakultas Dakwah Dan Komunikasi.

Lexy, J. M. (2001). Metodologi Penelitian Kualitatif. Bandung: Rosdakarya.

Marwan, M. R., \& Ahyad. (2017). Analisis Penyebaran Berita Hoax Di Indonesia. Universitas Gunadarma.

Mutmainnah. (2018). Respon Mahasiswa Jurusan Komunikasi Dan Penyiaran Islam UIN Alauddin Makassar Terhadap Hoax Di media Sosial. Makassar: Uin Alauddin Makassar.

Rifauddin, M., \& Halida, A. N. (2018). Waspada Cybercrime dan Informasi Hoax Pada Media Sosial Facebook. Khizanah Al-Hikmah, 98-111.

Sakti, B. C., \& Yulianto, M. (2018). Penggunaan Media Sosial Instagram Dalam Pembentukan Diri Remaja. Interaksi Online, 1-12.

Sianipar, A. P. (2013). Pemanfaatan Youtube Di Kalangan Mahasiswa. Jurnal Ilmu Komunikasi Flow, 1-10.

Sulistyo-Basuki. (1993). Pengantar Ilmu Perpustakaan . Jakarta: Gramedia Pustaka.

Syaifullah, I. (2018). Fenomena Hoax Di Media Sosial Dalam Pandangan Hermeneutika. Surabaya: Universitas Islam Negeri Sunan Ampel.

Trisnani. (2017). Pemanfaatan Whatsapp Sebagai Media Komunikasi Dan Kepuasan Dalam Penyampaian Pesan Dikalangan Tokoh Masyarakat. Jurnal Komunikasi, Media Dan Informatika, 1-12. 